\title{
Using Correlative, Mechanistic and Hybrid Niche Models to Predict the Productivity and Impact of Global Climate Change on Maize Crop in Brazil
}

\author{
João Carlos Nabout*, Jordana Moura Caetano, Rafael Batista Ferreira, \\ Itamar Rosa Teixeira \& Sueli Martins de Freitas Alves
}

Universidade Estadual de Goiás - UEG, Unidade Universitária de Ciências Exatas e Tecnológicas - UnUCET, Anápolis, GO, Brasil

\begin{abstract}
Ecological niche models (ENMs) can be used to investigate the shifts in geographical distributions and in productivity of cultivated species in future climatic scenarios. Such models can be classified in correlative, mechanistic or hybrid. The aim of this study was to investigate the relationship between productivity of Zea mays in Brazilian municipalities and crop suitability in current scenarios using the three different ENMs' types, as well as to predict the impacts of climate change on the geographic distribution of $Z$. mays in Brazil The mechanistic model used was Plantgro, the correlative one was Maxent, and to hybridize them we added the mechanistic model output as another predictor in a second Maxent model. The correlative and hybrid models were very similar, while the mechanistic model presented very distinct results from the other two models. The correlative (maxent) model was the best surrogate of maize productivity. The correlative model indicated that in the future there will be little change in environmental suitability in relation to the current climate.
\end{abstract}

Key words: Ecological Niche Model, Maxent, Plantgro Model, Zea mays.

\section{Introduction}

Ecological Niche Models (ENMs) have been widely used to investigate the shifts in potential geographical distribution of the species in future scenarios of climate change (Peterson et al. 2011). However, two different types of ENMs are available: the correlative and the mechanistic approaches (Franklin 2009). The correlative approach is more frequently used and starts by associating the current and known geographical occurrences of species with environmental geographical data to generate a suitability gradient that is projected in geographical space (Peterson et al. 2011). The mechanistic models, on the other hand, combine values from physiological characteristics of the species with environmental data to generate a predictive model (Kearney \& Porter 2009). Although there has been a recent dispute about the effectiveness of these two classes of ENMs (e.g., Buckley et al. 2010; Kearney \& Porter 2009), a possible consensus can be achieved by a new approach, the hybrid niche model, that uses the mechanistic model as another predictor in the correlative model (Buckley et al. 2011).

\footnotetext{
*Send correspondence to: João Carlos Nabout Universidade Estadual de Goiás - UEG, Unidade Universitária de Ciências Exatas e Tecnológicas - UnUCET, Rod BR-153, 3105, CEP 75132-903, Anápolis, GO, Brasil E-mail: joao.nabout@ueg.br
}

For most species it is difficult to obtain physiological tolerances in different environmental dimensions, hindering the use of mechanistic models (Araújo \& Peterson 2012). However, physiological information for cultivated species has long been available, so that the use of mechanistic, correlative or hybrid models for species of cultivated plants is feasible and reliable. Moreover, agriculture is one of the most vulnerable world's economic activities in relation to climate change and may suffer progressive declines in production in the coming years due to increased temperatures (Assad et al. 2008). Thus, the use of ENMs for cultivated species allows a better investigation of the impact of global climate change on these crops (e.g. Hijmans \& Graham 2006), in terms of distribution and even for crop productivity and for the economic impacts of such shifts (e.g. Nabout et al. 2011).

Considering the wide application of ENMs and the paucity of studies investigating the impact of climate change on crop plants (Beck 2012), the aim of this study was to investigate the relationship between productivity of Zea mays L. in Brazilian municipalities and crop suitability in current scenarios under the correlative, mechanistic and hybrid models, as well as to predict the impact of climate change on the geographic distribution of $Z$. mays using the ENMs. 


\section{Material and Methods}

\section{The species}

The species investigated in this study was Zea mays (maize), which has been widely cultivated in several regions of Brazil and throughout the world. The maize is currently the third most traded cereal, after wheat and rice (see www.fao.org). Brazil is the third largest maize producer, reaching 57,406,900 tons in 2010/2011 ( $1^{\text {st }}$ and $2^{\text {nd }}$ harvest), covering an area of 13,806,100 hectares (see historical series in http://www. conab.gov.br). This is an important cereal and its economic importance is well known and characterized by its use in various forms, ranging from food (human and livestock) to the high-tech industry (Pavão \& Ferreira Filho 2011).

Productivity data for maize at municipality scale was obtained from the relationship between production and harvested area. The production values and harvested area can be found at the Instituto Brasileiro de Geografia e Estatística (IBGE, www.ibge.gov.br) using the database "Sistema IBGE de Recuperação Automática" (SIDRA). We recorded the municipal agricultural production (tonnes) and their respective planted areas (ha) in the period 1994-2010.

\section{Ecological Niche Models}

We fitted here three ENMs approaches: Mechanistic, Correlative and Hybrid model. For the mechanistic model, we used Plantgro model (Hackett \& Vanclay 1998), in which requirements for plant growth are described as plateaushaped curves that indicate plant responses (expressed as 0 to 1 ) to monthly precipitation and minimum and mean temperature. This model is implemented in DIVA-GIS 7.3.0 (Hijmans et al. 2005) and uses environmental data of temperature and precipitation to determine fundamental niche of the species and project it in geographical space. These environmental data are defined by two parameters (absolute and optimal). The environmental data for this model were monthly temperature and precipitation, obtained at the site Worldclim (www.worldclim.org), with resolution of 0.0417 degrees. The mechanistic parameters for $Z$. mays were taken from the ECOCROP database (http://ecocrop.fao. org/), which includes killing (minimum) temperature, and minimum, maximum, and range of optimal temperatures, the minimum and maximum length of the growing season, and minimum, maximum and range of optimal amount of rainfall.

For the correlative models, we selected a total of 5391 Brazilian municipalities in which occurrences (productivity larger than zero) of this species were recorded and used as occurrence data. However, many points are very close geographically, and this can generate an effect of spatial dependence that may disturb model fit. To control for the effect of spatial dependence, we used Moran's I correlograms based on the environmental suitability obtained by an initial correlative model built using all data, and established at which distance the spatial correlogram crosses the intercept and thus define independently samples for modeling (see Tôrres et al. 2012). Based on such method, we defined $880 \mathrm{~km}$ as distance necessary to get 16 spatially independent presence points for maize (Figures S1 and S2 in the Additional Supporting Information available at www.abeco.org.br). The following environmental predictors were used to fit the model: temperature seasonality, isothermality, minimal temperature of coldest month, annual precipitation and precipitation of coldest quarter, all of them were obtained from Wordclim (www.wordclim.org), and were converted into a grid with 0.0417 degrees of resolution.

We used Jackknife criteria to selected environmental variables (see details in Nemésio et al. 2012) and then applied the Maximum Entropy algorithm (MAXENT; Phillips et al. 2006) to obtain the species' distribution. The input parameters followed the program defaults, apart from the iterations that were set to 1000 , with duplicates removed. Then we used the AUC (Area Under the - ROC - Curve) to evaluate the model (Peterson et al. 2011). Finally, for the hybrid model, we used the same environmental variables shown above and mechanistic model output obtained in the Plantgro model as another predictor in the MAXENT.

The same variables were used to project the ENMs model into future climate, derived from the global climate model CCCma (Canadian Centre for Climate Modelling and Analysis) for a pessimistic scenario (A2a) for 2050. The climatic data were obtained from Worldclim (www.worldclim. org), and all the climate variables were converted into a grid with 0.0417 degrees of resolution. It was projected to future scenario only the ENMs that best correlated with productivity (see data analysis).

\section{Data analysis}

The association between $Z$. mays productivity and environmental suitability (for each one of ENMs) was investigated using Pearson correlation approach, after log-transformation of both variables. The significance test for these correlations was based on the Dutilleul's correction for geographically effective degrees of freedom $\left(\mathrm{df}_{\text {Dutilleul }}\right)$ obtained in SAM v.4 Software (Rangel et al. 2010). Furthermore, the difference in climate suitability due to climate change was investigated by delta suitability of cities that produce maize.

We performed a Pearson correlation of maize yield with the year (for each municipality), so that positive values indicate temporal increase of productivity (kept planting area constant) and negative values suggest loss of productivity in time. This is relationship indicates the trend of productivity of municipality (hereafter called "productivity trends"). The current suitability was then geographically correlated to "Productivity trend" and to the change in suitability across municipalities, also using Dutilleul's correction. 


\section{Results}

The maize productivity was concentrated mainly in southern and southeastern Brazil (Figure 1a). Moreover, according to the map of suitability of correlative and hybrid model, only the Caatinga region (northeastern Brazil) do not exhibit favorable climatic conditions for the cultivation of maize (Figure 1b, c). On the other hand, in the mechanistic model the Caatinga region and southern Brazil has high environmental suitability whereas the northern region (Amazonia) shows low suitability, thus diverging strongly from the other two ENMs (Figure 1d). AUC from correlative and hybrid models were high and quite similar (0.945 and 0.949 , respectively).

Most municipalities have low productivity of maize and only a few municipalities have high productivity (3\% of municipalities produce more than 5 tons per hectare)
(Figure S3 in the Additional Supporting Information). Maize productivity was positively correlated with current suitability estimated by the correlative (Figure 2, $r=0.44$; $\left.P=0.02 ; \mathrm{df}_{\text {Dutilleul }}=15\right)$ and hybrid model $(\mathrm{r}=0.40$; $P=0.03 ; \mathrm{df}_{\text {Dutilleul }}=70$ ). Nonetheless, the correlation between productivity and mechanistic predictions was much lower and not significant $(r=-0.11 ; P=0.61$; $\left.\mathrm{df}_{\text {Dutilleul }}=18\right)$ (Figure 2).

The temporal trends in productivity of Brazilian municipalities reveal a general increase in productivity over the years, indicated by a mean positive correlation coefficient (Figure S4 in the Additional Supporting Information). The productivity trends was positively correlated with current environmental suitability $\left(\mathrm{r}=0.28 ; P=0.02 ; \mathrm{df}_{\text {Dutilleul }}=57\right)$. Thus, municipalities with higher increases in productivity tend to occur in regions of high environmental suitability.
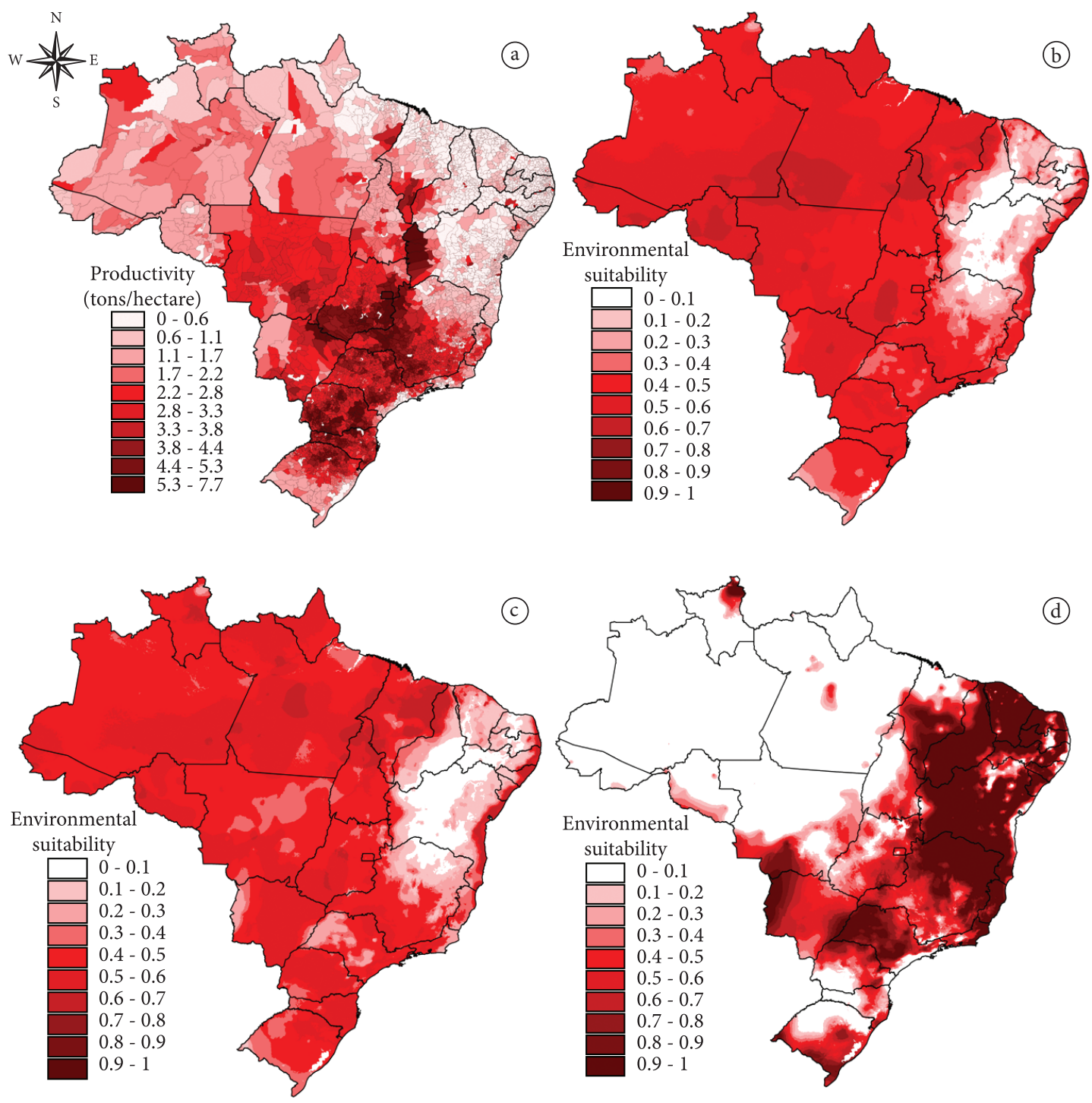

Figure 1. Map of Zea mays productivity in Brazilian municipalities (a), and environmental suitabilities for current time, generated using correlative (b) hybrid (c) and mechanistic models (d). 
The map of environmental suitability in future scenario (Figure 3), using correlative model only, indicated that there was little change in climatic suitability in relation to the current climate scenario. Actually, the map obtained in the current climate scenario is very similar to the map of future climate model (Pearson correlation $r=0.93$, $P<0.01)$. Moreover, the number of municipalities that will lose climatic suitability is similar to the number of

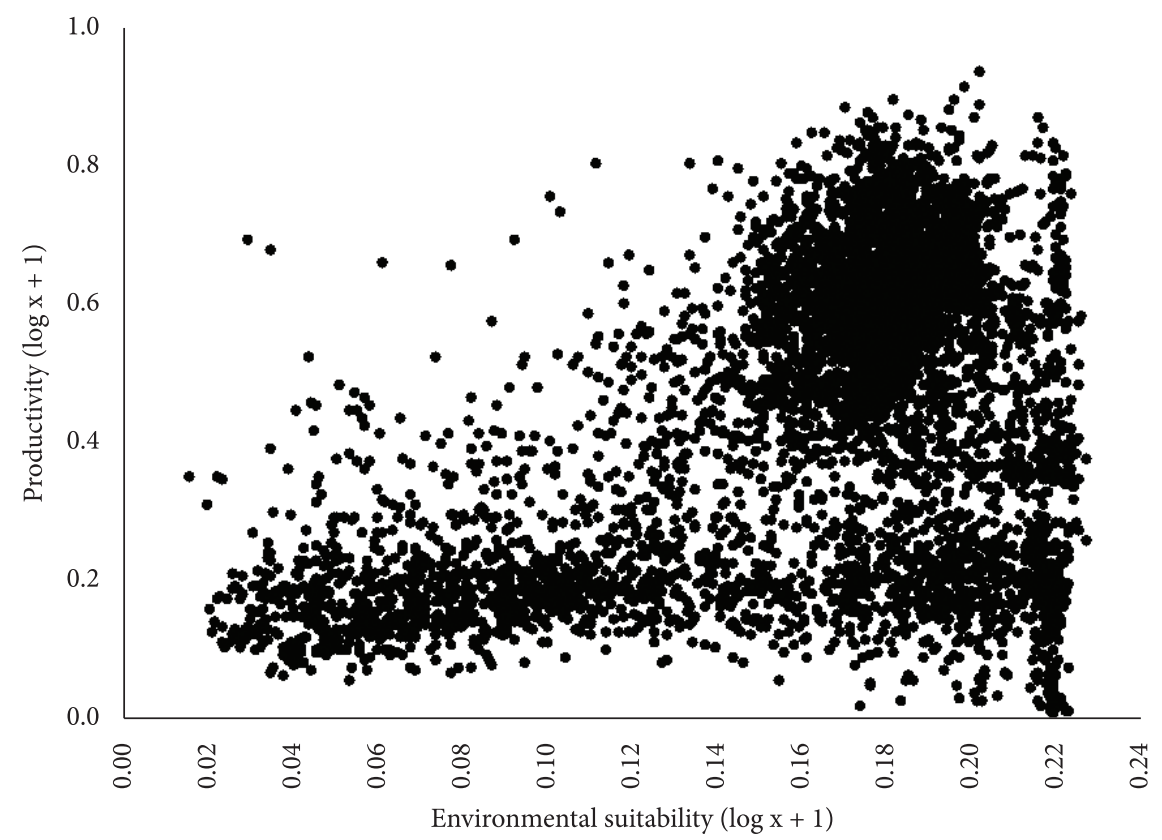

Figure 2. Relationship between the environmental suitability and the maize productivity $(\mathrm{r}=0.44 ; P=0.02$ with 15 geographically effective degrees of freedom) for all municipalities. Figure for hybrid model is qualitatively similar.

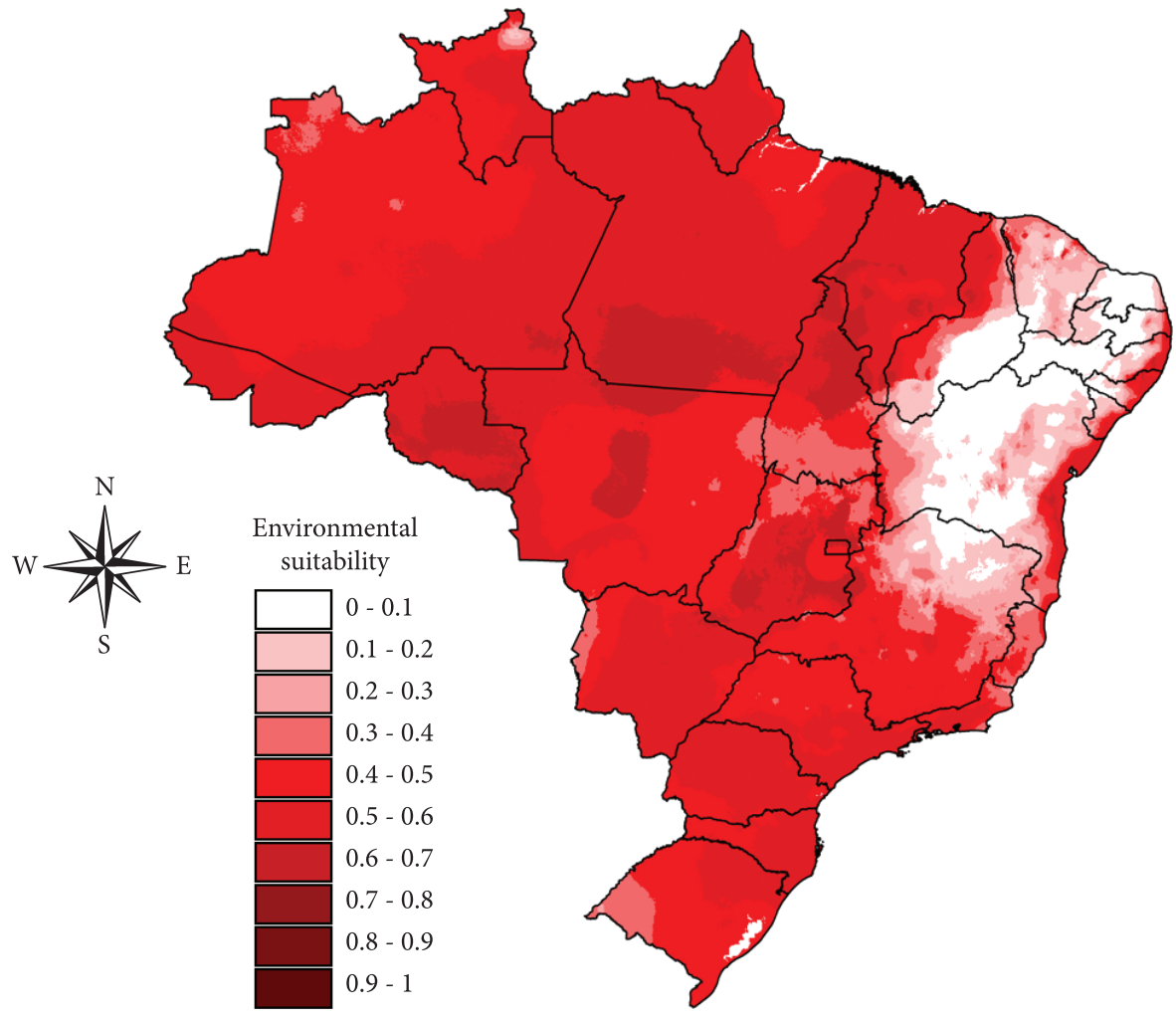

Figure 3. Map of environmental suitabilities of Zea mays for future time (2050), generated using correlative model. 
municipalities that will gain suitability (Figure S5 and S6 in the Additional Supporting Information). However, an evaluation by states of Brazil indicated that the "Rio Grande do Norte" is the State that presents greater loss of environmental suitability, whereas "Paraná" is the State with highest gain of suitability.

The productivity trends were positively correlated with the delta environmental suitability, although the correlation is low and only marginally significant $(r=0.18, P=0.15$, $\mathrm{df}_{\text {Dutilleul }}=51$ ). This suggests that the productivity today is higher in municipalities where gain in climatic suitability will occur in the future.

\section{Discussion}

The number of papers about ENMs has grown sharply in recent years (Peterson et al. 2011), but most of them used the correlative approach, most likely due to lack of physiological data required by mechanistic models (Araújo \& Peterson 2012). For the present study the correlative model was the best surrogate for productivity of maize in Brazilian municipalities and the incorporation of physiological data did not produced significant improvements in ENMs. Thus, for cultivated species, mechanistic models are not necessarily good to predicting productivity, and therefore are not useful to understand the impacts of global climate change. Certainly, the inclusion of new biophysical variables can improve the mechanistic model, but this is also valid for both the correlative and hybrid models, and indeed the inclusion of new types of variables is on the edge of research frontiers in all ENMs (Peterson et al. 2011). Also with respect to the mechanistic model, it is important to consider that the physiological data obtained for maize came from an international database (i.e. FAO) that combines physiological information of species from various countries. Therefore, local improvements can alter the physiological tolerance of this species, and the lack of theses local information may explain the low predictive power of the mechanistic model.

Considering the importance of correlative models and their good fit, based on our data and analyses, we recommend their use to investigate the potential geographical distribution of cultivated species. In this study we found a significant and positive correlation between productivity and climate, clearly suggesting that, despite strong technological investment in cultivated plants, the climate is still critical to the productivity and distribution of the species. Furthermore, it reinforces the importance of studies evaluating the effects of global climate change on cultivated species, since it may influence future productivity and, consequently, the economy at local, national and global scales (Hijmans \& Graham 2006).

However, it is important to keep in mind that the ENMs applied to native species has many problems and drawbacks (see Elith et al. 2010), and the situation tend to be even more complicate when they are applied to cultivated species (Beck 2012). In fact, cultivated species are strongly influenced (geographic distribution and productivity) by several factors usually not included as model predictors, such as resource biotech, irrigation, soil types and fertilization and other local factors (see Connor et al. 2011).

Although the use of ENMs for modeling cultivated species response is still scarce, there is great concern about the impacts of climate change on the distribution and physiology of these cultivated species (e.g. Beck 2012), with studies related to food safety (e.g. Ureta et al. 2012) and impact of pests in agriculture (e.g. Zhu et al. 2012). In general, studies that investigate the impact of climate change on cultivated species found a reduction in area of cultivation in future scenarios (Lane \& Jarvis 2007; Jarvis et al. 2008; Beck 2012; Ramirez-Villegas et al. in press). However, we found that climate change does not seem to exert a strong impact on the geographic distribution of maize.

Other studies have found different results for maize. Ureta et al. (2012), for instance, found significant reductions of potential distribution areas of Mexican maize races by 2030 and 2050. Assad et al. (2008) investigated the impact of global climate change in 9 cultivated species of Brazil, and in almost all cultures they predict a reduction in potential geographic distribution (excepted sugarcane), according to the model Precis (Providing Regional Climates for Impact Studies). Compared with the present study, Assad et al. (2008) found a greater reduction in the geographical distribution of maize in future scenarios of climate change (approximately $12 \%$ reduction in the geographical distribution). Nonetheless, the authors used different projection technique (i.e. Precis), as well as other predictors, so the results are hardly directly comparable. Also, it is important to keep in mind that niche model techniques are important sources of variation, driving large uncertainties in predictions (e.g. DinizFilho et al. 2010). The aims of this study was not to compare different techniques for ENMs, but future studies may focus on how different correlative models are correlated with productivity, with important applications to agricultural science. Depending on these results, this may also lead to recommending the use of ensemble forecasting approach (sensu Araújo \& New 2007) to reduce uncertainties in predictions of geographical distribution.

In present study the relationship between productivity and environmental suitability of correlative model can be better described as a constraint envelope, and not as a functional relationship. In this envelope, regions with low suitability will always minimally produce maize, whereas highly suitable regions can produce more or less maize. The low production of maize in areas of high suitability may also be related low support to exploitation of this crop by local governments and other economic and political problems, thus making the production of other crops (such as soybean and sugar cane) a more profitable investment. It is worthwhile to notice that researchers have investigated the relationship between environmental suitability obtained from ENMs and other characteristics of the species, such as genetic population structure (Diniz-Filho et al. 2009), functional traits (Thuiller et al. 2010), population density (Tôrres et al. 
2012), and fruit production of native plants (Nabout et al. 2011). Constraint envelopes were found in some of these papers (Tôrres et al. 2012; Nabout et al. 2011), demonstrating that the ENM in high environmental suitability does not make a good prediction of these demographic attributes for both native (other paper cited) and cultivated species (this study).

Here we compared three different types of ENMs and demonstrated the importance of them, particularly the correlative model, to understand the impact of global climate change on cultivated species. The use of ENM in cultivated species allows important strategies to minimize the economic impact of climate changes on agriculture, such as: i) change the cultivated species in areas that will have a reduction in the environmental suitability for a given species; ii) explore new potential regions for crops in future scenarios (e.g. Ureta et al. 2012), and; iii) indicate regions for development of programs for develop varieties tolerant to climate change. Moreover, the difficulties found to model the cultivated species are not different from those when modeling native species, so it is still necessary investigate the uncertainties of climate change impact on cultivated species (e.g. Ramirez-Villegas et al. in press). Finally, researchers who wish to use these ENMs to native or cultivated species should consider that Box (1979, p. 3) wrote: “[...] Models, of course, are never true, but fortunately it is only necessary that they be useful. For this it is usually needful only that they not be grossly wrong".

\section{Acknowledgements}

We acknowledge CAPES for scholarships granted to Jordana Moura Caetano, Rafael Batista Ferreira. Our work on ecological niche models and agriculture science has been continuously supported by different grants $\mathrm{CNPq}$. We thank José Alexandre Felizola Diniz-Filho, Paulo De Marco Júnior and Ricardo Dobrovolski for discussions and suggestions that improved previous versions of the manuscript.

\section{References}

Araújo MB \& Peterson AT, 2012. Uses and misuses of bioclimatic envelope modelling. Ecology, 93:1527-1539. PMid:22919900. http://dx.doi.org/10.1890/11-1930.1

Araújo MB \& New M, 2007. Ensemble forecasting of species distributions. Trends in Ecology and Evolution, 22:42-47. PMid:17011070. http://dx.doi.org/10.1016/j.tree.2006.09.010

Assad ED et al., 2008. Aquecimento Global e a Nova Geografia da produção Agrícola no Brasil. Brasília: Embaixada Britânica. PMCid:2646102.

Beck J, 2012. Predicting climate change effects on agriculture from ecological niche modeling: who profits, who loses? Climate Change. In press. http://dx.doi.org/10.1007/ s10584-012-0481-x

Box GEP, 1979. Some problems of statistics and everyday life. Journal of the American Statistical Association, 74:1-4. http:// dx.doi.org/10.1080/01621459.1979.10481600
Buckley LB et al., 2010. Can mechanism inform species' distribution models? Ecology Letters, 13:1041-1054. PMid:20482574.

Buckley LB et al., 2011. Does including physiology improve species distribution model predictions of responses to recent climate change? Ecology, 92:2214-2221. PMid:22352161. http://dx.doi.org/10.1890/11-0066.1

Connor DJ et al., 2011. Crop ecology: productivity and management in agricultural systems. Cambridge University Press.

Diniz-Filho JAF et al., 2009. Niche modelling and landscape genetics of Caryocar brasiliensis (Pequi tree: Caryocaraceae) in Brazilian Cerrado: an integrative approach for evaluating central-peripheral population patterns. Tree Genetics \& Genomes, 5:617-627. http://dx.doi.org/10.1007/ s11295-009-0214-0

Diniz-Filho JAF et al., 2010. Ensemble forecasting shifts in climatically suitable areas for Tropidacris cristata (Orthoptera: Acridoidea: Romaleidae). Insect Conservation and Diversity, 3:213-221. http://dx.doi. org/10.1111/j.1752-4598.2010.00090.x

Elith J, Kearney M \& Phillips S, 2010. The art of modelling range-shifting species. Methods in Ecology Evolution, 1:330342. http://dx.doi.org/10.1111/j.2041-210X.2010.00036.x

Franklin J, 2009. Mapping species distributions: spatial inference and prediction. Cambridge: Cambridge University Press.

Hackett C \& Vanclay JK, 1998. Mobilizing expert knowledge of tree growth with the PLANTGRO and INFER systems. Ecological Modelling, 106:233-246. http://dx.doi.org/10.1016/ S0304-3800(97)00185-3

Hijmans RJ \& Graham CH, 2006. The ability of climate envelope models to predict the effect of climate change on species distributions. Global Change Biology, 12:2272-2281. http:// dx.doi.org/10.1111/j.1365-2486.2006.01256.x

Hijmans RJ et al., 2005. Very high resolution interpolated climate surfaces for global land areas. International Journal of Climatology, 25:1965-1978. http://dx.doi.org/10.1002/ joc. 1276

Jarvis A, Lane A \& Hijmans RJ, 2008. The effect of climate change on crop wild relatives. Agriculture, Ecosystems \& Environment, 126:13-23. http://dx.doi.org/10.1016/j. agee.2008.01.013

Kearney M \& Porter W, 2009. Mechanistic niche modeling combining physiological and spatial data to predict species' ranges. Ecology Letters, 12:334-350. http://dx.doi. org/10.1111/j.1461-0248.2008.01277.x

Lane A \& Jarvis A, 2007. Changes in climate will modify the geography of crop suitability: agricultural biodiversity can help with adaptation. Journal of the Semi-Arid Tropics, 4:1-12.

Nabout JC et al., 2011.Global ClimateChangeandtheProductionof "Pequi" Fruits (Caryocar brasiliense) in the Brazilian Cerrado. Natureza \& Conservação, 9:55-60. http://dx.doi. org/10.4322/natcon.2011.006

Nemésio A et al., 2012. Searching for Euglossa cyanochlora Moure, 1996 (Hymenoptera: Apidae), one of the rarest bees in the world. Journal of Insect Conservation, 16:745-755. http://dx.doi.org/10.1007/s10841-012-9459-2 
Pavão AR \& Ferreira Filho JBS, 2011. Impactos econômicos da introdução do milho Bt11 no Brasil: uma abordagem de equilíbrio geral inter-regional. Revista de Economia e Sociologia Rural, 49: 81-108. http://dx.doi.org/10.1590/ S0103-20032011000100004

Peterson AT et al., 2011. Ecological niches and geographic distributions. Princeton: Princeton University Press. p. 314.

Phillips SJ et al., 2006. Maximum entropy modeling of species geographic distributions. Ecological Modeling, 190:231-259. http://dx.doi.org/10.1016/j.ecolmodel.2005.03.026

Rangel TF et al., 2010. SAM: a comprehensive application for Spatial Analysis in Macroecology. Ecography, 31:46-50. http://dx.doi.org/10.1111/j.1600-0587.2009.06299.x

Ramirez-Villegas J, Jarvis A \& Läderach P. 2011. Empirical approaches for assessing impacts of climate change on agriculture: The EcoCrop model and a case study with grain sorghum. Agricultural and Forest Meteorology. In press. http://dx.doi.org/10.1016/j.agrformet.2011.09.005

Thuiller W et al., 2010. Variation in habitat suitability does not always relate to variation in species' plant functional traits. Biology Letters, 23:120-123. PMid:19793738. PMCid:2817270. http://dx.doi.org/10.1098/rsbl.2009.0669

Tôrres NM et al., 2012. Can species distribution modelling provide estimates of population densities? A case study with jaguars in the Neotropics. Diversity and Distributions, 18:615627. http://dx.doi.org/10.1111/j.1472-4642.2012.00892.x

Ureta C et al., 2012. Projecting the effects of climate change on the distribution of maize races and their wild relatives in Mexico. Global Change Biology, 18:1073-1082. http:// dx.doi.org/10.1111/j.1365-2486.2011.02607.x

Zhu G et al., 2012. Potential Geographic Distribution of Brown Marmorated Stink Bug Invasion (Halyomorpha halys). PLoS ONE, 7(2):e31246. http://dx.doi.org/10.1371/ journal.pone.0031246

Received: October 2012

First Decision: November 2012

Accepted: November 2012 